\title{
A INDETERMINAÇÃO DO SUJEITO NO PORTUGUÊS BRASILEIRO: INVESTIGANDO ALGUMAS ESTRATÉGIAS PRONOMINAIS EM ORAÇÕES FINITAS
}

\author{
SUBJECT INDETERMINATION IN BRAZILIAN \\ PORTUGUESE: INVESTIGATING SOME \\ PRONOMINAL STRATEGIES IN FINITE CLAUSES
}

\author{
Gabriel de Ávila Othero* \\ UFRGS
}

\section{Susana Miranda da Silva** UFRGS}

Resumo: Neste artigo, analisamos estratégias de indeterminação do sujeito em orações finitas do português brasileiro (PB), por meio da investigação de um corpus recente de língua falada, o corpus LínguaPOA, que contém fala transcrita e coletada entre 2015 e 2016 em entrevistas sociolinguísticas. A ideia básica aqui é descrevermos e elencarmos as estratégias de indeterminação do sujeito em PB falado contemporâneo, com o intuito de verificarmos se a hipótese de Duarte (1995, 2007, 2012, entre outros) de que o PB passou a privilegiar orações com sujeito determinado pronominal explícito também se verifica em estratégias de indeterminação do sujeito. Além de investigarmos o corpus e analisarmos as estratégias de indeterminação do sujeito, comparamos nossos resultados com os resultados reportados por Vargas (2010, 2012), que investigou a indeterminação do sujeito em um corpus de língua escrita para peças de teatro do início da década de 1990. Nosso principal objetivo com a comparação entre essas duas sincronias (década de 1990 e anos 2015-2016) é iniciar o que pode ser uma análise contrastiva para verificar se houve mudança nas estratégias pronominais de referência arbitrária utilizadas para indeterminar o sujeito, além de verificar se há preferência pelo emprego da forma pronominal nula ou preenchida nas estratégias de indeterminação do sujeito em PB nessas duas sincronias. Argumentamos que a entrada de novas formas de indeterminação no sistema gramatical do PB e a preferência pelo uso de formas plenas dos pronomes de referência arbitrária (como mostraremos) são indícios da mudança pela qual o PB vem passando no que diz respeito ao favorecimento do sujeito expresso em detrimento do sujeito nulo. Relacionamos nossos achados empíricos ao efeito cascata de mudança já antecipado

\footnotetext{
* Doutor em Linguística pela Pontifícia Universidade Católica do Rio Grande do Sul (PUCRS). Professor Associado do Instituto de Letras da Universidade Federal do Rio Grande do Sul (UFRGS). ORCID: https://orcid.org/0000-0002-2060-6312. E-mail: gabriel.othero@ufrgs.br.

** Mestranda em Linguística pelo Programa de Pós-Graduação em Letras da Universidade Federal do Rio Grande do Sul (UFRGS). E-mail: susy.s@hotmail.com.
} 
por Labov (2008), em que mudanças no quadro pronominal do PB, em especial aquelas que foram se estabelecendo a partir da metade do século XX, afetam diferentes aspectos da gramática da língua, tal como as estratégias de indeterminação do sujeito.

Palavras-chave: Indeterminação do sujeito. Português brasileiro. Orações finitas. Pronomes. Referência arbitrária.

\begin{abstract}
In this article we analyze strategies of subject indetermination in finite clauses in Brazilian Portuguese (BP), through the investigation of a recent spoken language corpus, LinguaPOA, that contains transcribed speech, collected between 2015 and 2016 from sociolinguistic interviews. The basic idea here is to describe and list the strategies of subject indetermination in contemporary spoken BP in order to verify if Duarte's (1995, 2007, 2012, among others) hypothesis that BP is privileging clauses with overt pronominal determinate subject is also valid with indeterminate subjects. In addition to investigating the corpus and analyzing strategies of subject indetermination, we compare our results to those found by Vargas (2010, 2012), who investigated subject indeterminacy in a written language corpus composed by theatre plays from the early 1990s. Our main goal comparing these two synchronisms (early 1990s and 2015-2016) is to start a contrastive analysis to verify whether there has been a change in the pronominal arbitrary reference strategies used to indeterminate the subject, in addition to check whether there is a preference for null or overt pronominal form in strategies of subject indetermination in BP in these two synchronies. We argue that the entry of new forms of indetermination in the BP grammar system and the preference for the use of overt pronouns for arbitrary reference (as we will show) are an indication of the change that BP has been going through in terms of favoring the expressed subject over the null subject. We relate our empirical findings to the cascade effect already anticipated by Labov (1972), in which changes in the pronominal framework of BP, especially those that have been established since the middle of the 20th century, affect different aspects of the grammar of the language, such as strategies of subject indetermination.
\end{abstract}

Keywords: Subject indetermination. Brazilian Portuguese. Finite clauses. Pronouns. Arbitrary reference.

\title{
INTRODUÇÃO
}

Neste artigo, investigamos as estratégias de indeterminação do sujeito em orações finitas do português brasileiro (PB). Para isso, analisamos um corpus de língua falada recente, o corpus LínguaPOA, ${ }^{1}$ que contém fala transcrita e coletada entre 2015 e 2016 em entrevistas sociolinguísticas. Temos por objetivo principal elencar e descrever as estratégias de indeterminação do sujeito em PB falado contemporâneo (ao menos na variedade investigada). Além disso, iremos verificar se a hipótese central defendida por Duarte de que o PB passou a privilegiar orações com sujeito determinado pronominal explícito (em detrimento do sujeito nulo) também se verifica em orações com sujeito indeterminado (DUARTE, 1993, 1995, 2003, 2007; BERLINK; DUARTE; OLIVEIRA, 2015, entre outros).

Além de investigarmos o corpus e analisarmos as estratégias de indeterminação do sujeito, também iremos comparar nossos resultados com aqueles encontrados por Vargas (2010, 2012), que investigou estratégias de indeterminação do sujeito em um corpus de língua escrita

\footnotetext{
${ }^{1}$ LínguaPOA é um acervo de entrevistas sociolinguísticas de informantes da cidade de Porto Alegre e faz parte do projeto Variação fonético-fonológica e classe social na comunidade de fala de Porto Alegre (BATTISTI et al., 2017).
} 
para peças de teatro do início da década de $1990 .{ }^{2}$ A escrita monitorada é mais conservadora do que a fala espontânea e, por isso, costuma registrar "momentos anteriores" da fala em PB, privilegiando, muitas vezes, a norma lusitana em detrimento das inovações que encontramos na fala vernacular brasileira (conforme resultados encontrados em CYRINO, 1997; DUARTE, 2007; OTHERO et al., 2018; OTHERO; SPINELLI, 2019, por exemplo). Contudo, o texto escrito para o teatro deixa transparecer marcas de oralidade características do PB contemporâneo (DUARTE, 2012). Nossa principal motivação ao compararmos essas duas sincronias (início da década de 1990 e anos 2015-2016) é iniciar uma análise contrastiva para verificar se houve mudança nas estratégias pronominais de referência arbitrária utilizadas para indeterminar o sujeito e, como dissemos anteriormente, verificar se há preferência pelo emprego da forma pronominal nula ou plena nas estratégias de indeterminação do sujeito em $\mathrm{PB}^{3}$.

A forma pronominal nula é a regra em português europeu - PE (DUARTE, 2007, DUARTE; FIGUEIREDO SILVA, 2016). Desse modo, o sujeito nulo segue como estratégia gramatical produtiva em PE, tanto em construções com sujeitos determinados como com sujeitos indeterminados (ou arbitrários). A inovação em PB, como diversos estudos têm mostrado desde as investigações pioneiras de Duarte $(1989,1993)$, são as orações com sujeito foneticamente explícito de referência indeterminada (em detrimento de orações com sujeito nulo), como vemos em exemplos "canônicos" - (1) e (2) - retirados de uma gramática normativa tradicional, em contraste com os exemplos em PB contemporâneo, extraídos do corpus LínguaPOA - (3) e (4).

(1) Reputavam-no o maior comilão da cidade. (CUNHA; CINTRA, 2013, p. 142).

(2) Precisa-se do carvalho; não se precisa do caniço. (CUNHA; CINTRA, 2013, p. 142).

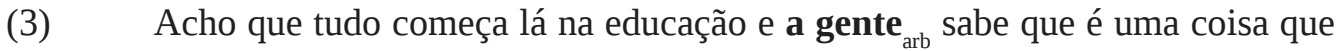
no Brasil tá completamente:: largado, né.

(4) Antigamente $\mathbf{e l e s}_{\text {arb }}$ faziam tudo::, tudo só na mão, assim, eles ${ }_{\text {arb }}$ escreviam as receitas e não tinha internet, não tinha Google pra pesquisar.

Repare que, em (1) e (2), não há sujeito pronunciado, ao contrário do que vemos nos exemplos (3) e (4), em que os pronomes a gente e eles têm uma interpretação arbitrária, atuando como sujeitos indeterminados (i.e. os pronomes perdem seu caráter referencial e passam a ser usados de maneira indeterminada ou arbitrária; por isso, assinalamos o índice subscrito arb ao lado da forma pronominal que marca a indeterminação do sujeito): em (3) o pronome $a$ gente não engloba nenhuma referência possível de $1^{\mathrm{a}}$ pessoa de plural canônica (i.e. $1^{\mathrm{a}} \mathrm{p} .+2^{\mathrm{a}}$ p., $1^{\text {a }}$ p. $+3^{\text {a }}$ p. ou $1^{\text {a }}$ p. $+2^{\text {a }}$ p. $+3^{\text {a }}$ p.), e a oração poderia ser parafraseada como "sabe-se que [a educação] é uma coisa que...”; da mesma forma, eles, em ambas as ocorrências em (4), não tem qualquer referência determinada, apenas genérica ou arbitrária; se ocultado, seria um sujeito

\footnotetext{
${ }^{2}$ Trata-se de três peças teatrais de autoria de Miguel Falabella: A partilha (1990), No coração do Brasil (1992) e Como encher um biquíni selvagem (1992). Essa amostra faz parte de um estudo diacrônico que analisou a indeterminação do sujeito por meio de peças teatrais escritas no período de 1837 a 1992 (VARGAS, 2010, 2012).

${ }^{3} \mathrm{O}$ ideal, como nos apontou um dos pareceristas do texto, seria comparar o que encontramos aqui com os dados de fala de outro corpus de Porto Alegre de momentos anteriores, como o VARSUL da década de 1990. Pretendemos fazer isso como trabalho futuro. Por ora, interessava-nos investigar o momento sincrônico do português com relação à referência arbitrária do sujeito e, se possível, comparar com algum momento anterior, apenas com o intuito de verificar se descobrimos novas estratégias ou se antigas estratégias haviam se perdido ou se fortalecido. Encontramos o trabalho de Vargas, que serviu de comparativo suficiente para este estudo.
} 
indeterminado canônico reconhecido pela tradição gramatical como tal (antigamente Ø faziam tudo, Ø escreviam as receitas).

Ainda que construções como (3) e (4) sejam comuns em PB - como mostraremos nas próximas seções -, a tradição gramatical insiste em afirmar que as estratégias de indeterminação em português acontecem apenas em "[...] casos em que o sujeito não vem expresso na oração nem pode ser identificado” (CUNHA; CINTRA, 2013, p. 142), tais como os exemplos (1) e (4). Isso se deve, obviamente, ao "modelo de língua” usado para a análise tradicional, a língua escrita literária ${ }^{4}$.

Dito isso, organizamos este artigo como segue: na primeira seção, apresentamos o fenômeno da indeterminação do sujeito e estudos sobre as formas pronominais de referência arbitrária no PB. Na segunda seção, apresentamos os resultados de Vargas (2010, 2012) em sua análise de peças de teatro (a que chamaremos aqui de Amostra 1990), tanto para as estratégias de indeterminação quanto para a representação das formas nulas ou preenchidas. Na terceira seção, apresentamos os resultados que obtivemos a partir de nossa análise do corpus LínguaPOA, que constitui o que chamaremos aqui de Amostra 2015. Finalmente, na quarta seção, trazemos um comparativo entre os resultados das duas amostras (que apresentam uma diferença cronológica de cerca de 25 anos, além da diferença de modalidade "língua escrita para ser falada” x "fala transcrita”) e esboçamos algumas generalizações.

\section{A INDETERMINAÇÃO DO SUJEITO NO PB}

Comecemos com o que encontramos na tradição gramatical portuguesa - e brasileira -, que reconhece duas formas de indeterminação do sujeito em orações finitas. O emprego do verbo na $3^{\mathrm{a}}$ pessoa do plural com o pronome não expresso (exemplo (1)) ou a $3^{\mathrm{a}}$ pessoa do singular acompanhada pela partícula se - quando o verbo for intransitivo ou intransitivo indireto - exemplos (2) e (5):

(1) Reputavam-no o maior comilão da cidade.

(2) Precisa-se do carvalho; não se precisa do caniço.

(5) Ainda se vivia num mundo de certezas. (CUNHA; CINTRA, 2013, p. 142).

São privilegiadas, portanto, as formas de indeterminação do sujeito que omitem o sujeito (seja uma forma pronominal ou SN nucleado por substantivo) ou que empregam o clítico se como índice de indeterminação do sujeito. Contudo, ao longo das últimas décadas, diversos estudos sobre o tema (conforme referências mencionadas na seção anterior, por exemplo) demonstraram que tanto na língua falada como na escrita (em diversos gêneros) o PB apresenta outras estratégias para indeterminar o sujeito (veja algumas estratégias em Perini, 2016, que mencionamos há pouco, por exemplo). Entre essas outras estratégias, está o uso de formas pronominais, alvo de nossa investigação aqui.

\footnotetext{
${ }^{4}$ Por outro lado, as gramáticas contemporâneas do PB que fogem à tradição gramatical apresentam o fenômeno da indeterminação do sujeito de maneira mais afinada com os fatos da língua. Perini (2016, p. 112-116), por exemplo, reconhece pronomes pessoais (e outros sintagmas nominais) como recursos sintáticos que expressam a indeterminação do sujeito em PB e apresenta exemplos como: "É muito mais fácil você fazer uma campanha de vacinação do que você manter um paciente na UTI", em que o sujeito indeterminado é expresso pelo pronome você de referência indeterminada ou arbitrária.
} 
Na literatura linguística brasileira, estudos variacionistas, como Setti (1998) e Barros Jesus (2017), analisaram as formas pronominais que têm sido usadas de maneira frequente na indeterminação do sujeito e fatores linguísticos e sociais que estão diretamente relacionados ao fenômeno. Aliando pesquisas sociolinguísticas ao modelo gerativista de Princípios e Parâmetros, Duarte $(1993,1995,2003,2007)$ e Vargas $(2010,2012)$ associam a representação dos sujeitos indeterminados pronominais à mudança na marcação do parâmetro do sujeito nulo. Segundo o que eles reportam (e como veremos aqui em nossa investigação própria), o PB inclui, entre suas estratégias de indeterminação do sujeito, o uso dos pronomes a gente, nós, tu, você e eles, além das estratégias já reconhecidas pela tradição gramatical. É o que vemos nos exemplos a seguir (retirados do corpus LínguaPOA, a Amostra 2015):

(6) Meu pai sempre me dizia que a paciência é uma das maiores virtudes do homem. A gente ${ }_{\text {arb }}$ tem que aprender a esperar pelo futuro.

(7) [...] então, de repente, nós ${ }_{\text {arb }}$ podíamos falar, $\varnothing_{\text {arb }}$ podíamos berrar, $\varnothing_{\text {arb }}$ podíamos cantar, $\varnothing_{\text {arb }}$ podíamos tudo [...].

(8) Então, assim, $t u_{\text {arb }}$ nunca sabe se aquilo ali que tá sendo falado é a realidade, se aquilo ali foi uma coisa montada pra aquele momento, sabe?

Aqui os pronomes a gente, tu e nós não têm referência determinada, mas arbitrária, ou indeterminada, tal como já observáramos em (3) e (4). Em (6) e (7), os pronomes de primeira pessoa do plural não têm referência definida identificável, ou seja, não delimitam um agrupamento que englobe o falante e seu interlocutor ou o falante e mais algum grupo de pessoas; antes, eles têm uma referência indeterminada que significa algo como "todas as pessoas neste contexto”. Em (8), o falante não está se referindo a seu interlocutor, mas a qualquer pessoa, ou seja, é um tu que tem valor de sujeito indeterminado.

Vargas (2010) realizou um estudo diacrônico, em que investigou as estratégias de indeterminação do sujeito em peças teatrais cariocas dos séculos XIX e XX. Ela então elencou as estratégias da expressão da referência arbitrária em sentenças finitas e não finitas em PB e encontrou um total de 958 ocorrências de estruturas com sujeitos indeterminados. Dessas, 89,5\% (859 ocorrências) apresentaram-se em orações finitas e 10,5\% (99 ocorrências) em orações não finitas, que foram analisadas e distribuídas em sete períodos de tempo ${ }^{5}$. Apresentamos aqui os resultados obtidos para as orações finitas ${ }^{6}$ (nosso objeto de investigação neste momento), representados no Gráfico 1.

\footnotetext{
${ }^{5}$ A distribuição das peças em períodos de tempo foi a seguinte: período I (1839-1847), período II (1860-1889), período III (19181920), período IV (1933-1949), período V (1945-1955), período VI (1975-1979) e período VII (1990-1992). O critério para a distribuição dos períodos foi o equilíbrio no número de dados (VARGAS, 2010, 2012).

${ }^{6}$ Como não trataremos das orações não finitas neste estudo, optamos por detalhar apenas os resultados para as orações finitas.
} 
Gráfico 1: Distribuição dos sujeitos de referência [+arb] por período de tempo em sentenças finitas

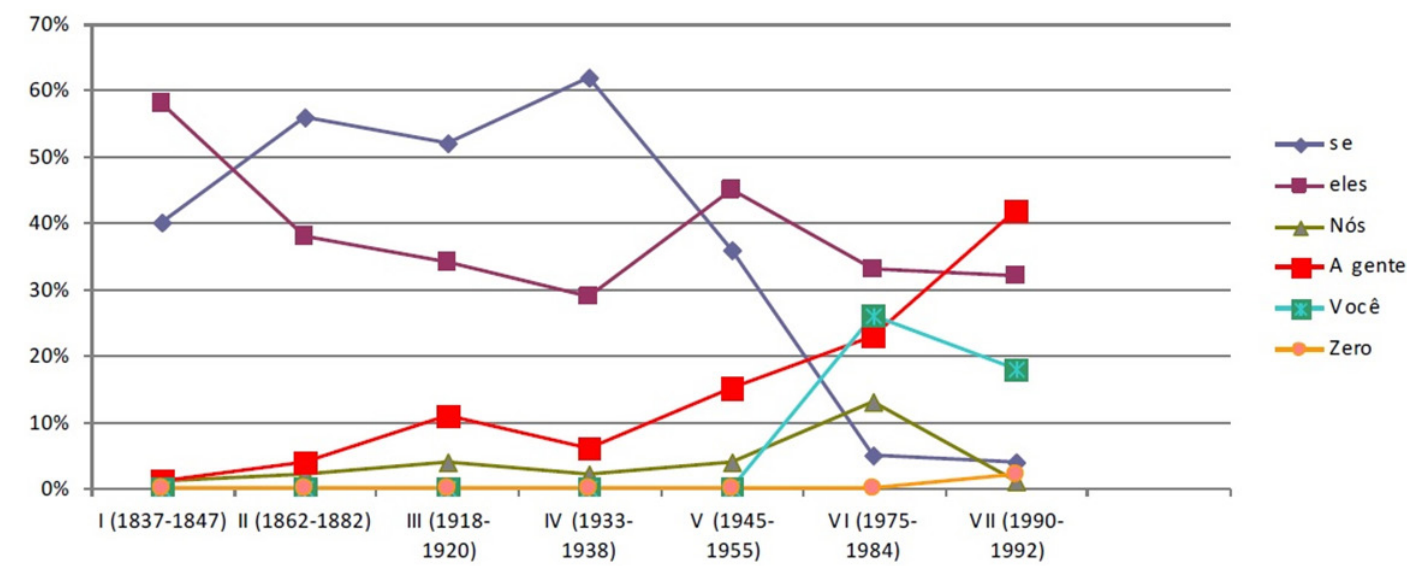

Fonte: Adaptado de Vargas (2010, p. 60).

No Gráfico 1, podemos observar que, além das estratégias com verbo na $3^{\mathrm{a}}$ pessoa do plural e do emprego do verbo na $3^{\mathrm{a}}$ pessoa do singular com o clítico se, reconhecidas pela tradição gramatical, como vimos, aparecem, mesmo que com índices muito baixos nas peças mais antigas, outras estratégias de indeterminação do sujeito, envolvendo pronomes. Por um lado, estas passam a ser mais frequentes ao longo do tempo (repare, por exemplo, no uso de a gente, que tem crescimento acentuado a partir da metade do século XX). A estratégia com o clítico se, por outro lado, apresenta um decréscimo significativo nesse mesmo período.

Quanto à representação nula versus plena das formas pronominais, Vargas (2010) apresenta os seguintes resultados para os pronomes nominativos de indeterminação eles, nós, $a$ gente e você (Gráfico 2).

Gráfico 2: Os pronomes eles, nós, a gente e você marcando o sujeito indeterminado

\section{A distribuição geral das formas plenas de indeterminação}

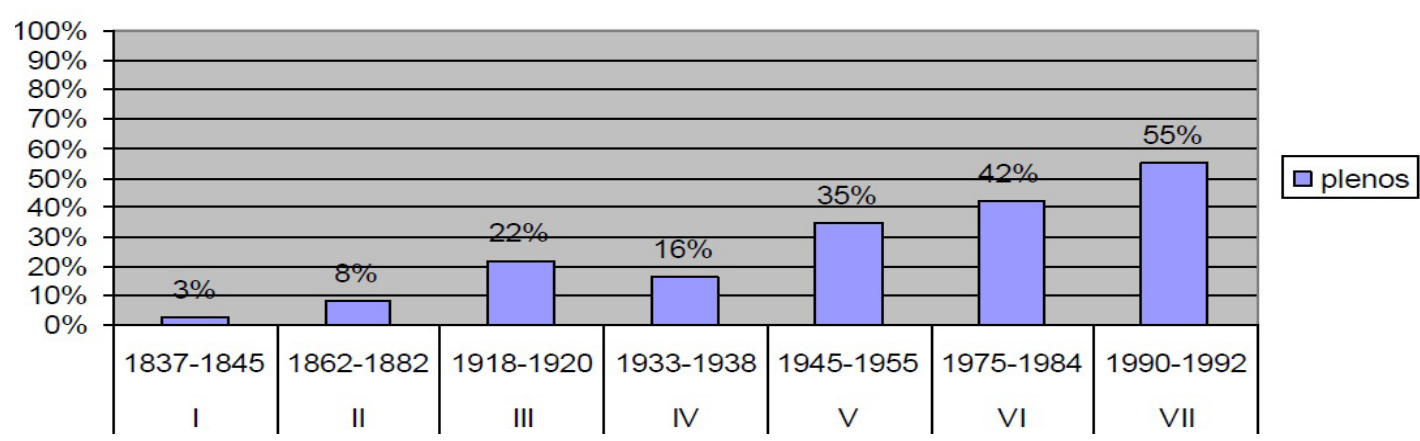

Fonte: Adaptado de Vargas (2010, p. 67).

É possível observar claramente o aumento, ao longo do tempo, da preferência pela forma foneticamente preenchida para a expressão dos sujeitos pronominais indeterminados em PB. Daí Vargas (2012) conclui que 
[...] em relação aos sujeitos de referência arbitrária em sentenças finitas, constatamos que, até a década de 1950, a preferência é realmente pelo uso de se indefinido e pela $3^{\mathrm{a}}$ pessoa do plural. Nos dois períodos subsequentes, observou-se

(a) uma queda brusca do se;

(b) a resistência da $3^{\text {a }}$ pessoa do plural para o tipo de indeterminação que exclui o falante em construções com verbo no pretérito perfeito;

(c) a implementação gradativa da estratégia com a gente, que alcança seu ponto mais alto no último período, se tornando a estratégia mais empregada nessa sincronia;

(d) a entrada da forma você a partir do período VI (década de 1970) com índices bastante expressivos e sua permanência no período VII;

(e) a inexpressiva ocorrência (três dados) da estratégia com o verbo na $3^{\mathrm{a}}$ pessoa do singular e uma posição vazia. (VARGAS, 2012, p. 66).

Veremos como essas tendências se apresentam em dados de fala do português brasileiro contemporâneo (na Amostra 2015), na terceira seção. Antes, vejamos com mais detalhes (na segunda seção) os dados e resultados de Vargas (2010) a partir de sua análise de peças de teatro da década de 1990 - o último período pesquisado por ela e, por isso, o mais próximo do investigado por nós.

\section{OS RESULTADOS DA AMOSTRA 1990}

Nesta seção, voltaremos nossa atenção aos resultados apresentados por Vargas (2010, 2012) nas peças que correspondem ao período VII da análise (veja Gráfico 1, na página anterior, e Tabela 1, a seguir). Correspondem a esse período 147 ocorrências de estruturas com sujeitos indeterminados. ${ }^{7}$

Tabela 1: Distribuição dos pronomes plenos (vs. total: nulos + plenos) ao longo do tempo

\begin{tabular}{r|r|r|r|r|r|r|r}
\hline Estratégia & $\mathrm{I}$ & $\mathrm{II}$ & $\mathrm{III}$ & $\mathrm{IV}$ & $\mathrm{V}$ & $\mathrm{VI}$ & $\mathrm{VII}$ \\
\hline Eles & $1 / 74$ & $1 / 52$ & $0 / 47$ & $1 / 38$ & $11 / 51$ & $3 / 31$ & $5 / 38$ \\
& $(1 \%)$ & $(2 \%)$ & $(0 \%)$ & $(3 \%)$ & $(22 \%)$ & $(10 \%)$ & $(13 \%)$ \\
\hline Nós & $0 / 0$ & $0 / 0$ & $1 / 5$ & $0 / 0$ & $0 / 0$ & $3 / 12$ & $1 / 1$ \\
& $(0 \%)$ & $(0 \%)$ & $(20 \%)$ & $(0 \%)$ & $(0 \%)$ & $(25 \%)$ & $(100 \%)$ \\
\hline A gente & $1 / 1$ & $4 / 5$ & $14 / 15$ & $8 / 9$ & $14 / 17$ & $15 / 21$ & $39 / 51$ \\
& $(100 \%)$ & $(80 \%)$ & $(93 \%)$ & $(88 \%)$ & $(82 \%)$ & $(71 \%)$ & $(76 \%)$ \\
\hline Você & $0 / 0$ & $0 / 0$ & $0 / 0$ & $0 / 0$ & $0 / 0$ & $16 / 24$ & $33 / 46$ \\
& $(0 \%)$ & $(0 \%)$ & $(0 \%)$ & $(0 \%)$ & $(0 \%)$ & $(67 \%)$ & $(72 \%)$ \\
\hline
\end{tabular}

Fonte: Adaptado de Vargas (2010, p. 69).

\footnotetext{
${ }^{7}$ A autora não específica quantas ocorrências correspondem a sentenças finitas e não finitas.
} 
A estratégia de indeterminação com se ( $3^{\mathrm{a}}$ pessoa do singular + clítico) apresenta apenas 4\% de ocorrência no período - queda brusca em relação aos 36\% do período V (conforme Gráfico 1). A autora ainda destaca que o predomínio, nesses 4\%, é de "frases feitas" ou "formas fixas”, como nunca se sabe ou não se fala mais nisso. A estratégia de indeterminação com o verbo na $3^{\text {a }}$ pessoa do plural representa 32\% das ocorrências, mantendo-se estável em relação ao período VI, e continua servindo como uma forma de indeterminação do sujeito que exclui o falante.

Quanto à estratégia com a $1^{\mathrm{a}}$ pessoa do plural (nós), verifica-se 1\% de ocorrência - índice baixo como na maior parte dos períodos analisados - acompanhando a tendência da língua oral hoje tanto para a referência definida quanto arbitrária de usar a gente no lugar de nós (LOPES, 1999, 2003, 2007; MENDONÇA, 2020; MENON, 1995; MONTEIRO, 1994). Duarte (1993, 1995) relaciona essa queda expressiva do nós à redução nos paradigmas flexionais do PB e à substituição cada vez mais frequente do pronome nós pela forma a gente, que se implementa lentamente ao longo dos períodos analisados e alcança o índice mais alto no período VII, correspondendo a 42\% das ocorrências (conforme, nesse sentido, ZILLES, 2002; OTHERO; CARDOZO, 2017, além das demais referências citadas neste parágrafo).

A entrada da forma pronominal você no quadro de pronomes em PB e sua subsequente utilização como estratégia de indeterminação do sujeito na língua ocorre somente no período VI, com índices expressivos (26\%), mas apresenta, no período VII, ligeira queda para 18\%. É no período VII também que ocorre a entrada da estratégia com o verbo na $3^{\mathrm{a}}$ pessoa do singular e uma posição vazia, sem associação a qualquer índice de indeterminação - referida aqui como forma zero por Vargas - com apenas 2\% de ocorrências (ver Gráficos 1 e 2). Segundo Vargas (2010), essa estratégia é empregada em contextos bastante específicos, relativos a discursos de procedimentos ou veiculando as categorias aspecto ou modalidade, como vemos nestas ocorrências, extraídas de Vargas (2012, p. 59):

Adalberto, pega um pouco deste cascalho aí, faz uma trouxinha no lenço e reserva, que eu vou levar de lembrança. __ Diz que a terra daqui é santa.

Me prometeram um lugar de atendente de dentista em Olaria. _ Tem que aprender a mexer com aqueles ferrinhos, mas o salário parece que compensa.

Quanto à representação nula versus plena das formas pronominais nominativas de indeterminação, é no período VII que ocorre o marco da prevalência das formas plenas sobre as nulas. Embora, nos períodos anteriores, as formas plenas estivessem em crescimento constante, é somente na Amostra 1990 que elas atingem um índice superior de frequência ao das formas nulas, chegando aos 55\%, conforme apontam os dados do Gráfico 2. A distribuição das formas plenas, para todos os períodos, encontra-se na Tabela 1. No caso dos sujeitos de referência definida, conforme mostram os dados de Duarte (1993, 1995), essa prevalência ocorreu no período anterior. O período VII marca então a preferência pelo emprego das formas plenas, tanto definidas quanto arbitrárias, uma tendência que permanece, como veremos na próxima seção, na Amostra 2015. 


\section{OS RESULTADOS DA AMOSTRA 2015}

A amostra analisada constitui-se de quatro entrevistas orais transcritas do acervo LínguaPOA, em que encontramos 227 ocorrências de sujeitos indeterminados em sentenças finitas. Começamos a descrição dos resultados montando uma tabela que apresenta a distribuição das estratégias de indeterminação que encontramos no corpus. São elas: eu, tu/você, nós, a gente, vocês, eles, se, zero. ${ }^{8}$ As formas nominativas podem aparecer nulas ou expressas, tal como mostraremos na sequência da análise e na Tabela 2.

Tabela 2: Distribuição dos sujeitos de referência arbitrária

\begin{tabular}{c|c|c}
\hline Estratégia & Ocorrências & $\mathbf{\%}$ \\
\hline tu/você & 69 & 30,3 \\
\hline zero & 57 & 25,1 \\
\hline a gente & 50 & 22,0 \\
\hline nós & 19 & 8,3 \\
\hline eles & 16 & 7,0 \\
\hline se & 8 & 3,5 \\
\hline vocês & 5 & 2,2 \\
\hline eu & 3 & 1,3 \\
\hline Total & $\mathbf{2 2 7}$ & $\mathbf{1 0 0}$
\end{tabular}

Fonte: Os autores.

Em primeiro lugar, destacamos a estratégia de indeterminação com os pronomes tu/você para a $2^{\mathrm{a}}$ pessoa do singular, que representam quase $1 / 3$ das ocorrências de sujeitos indeterminados do corpus, seja com pronome expresso (11), seja com uma retomada anafórica nula (12), ${ }^{9}$ como mostramos nos exemplos a seguir, extraídos da Amostra 2015:

(11) Então, assim, $t u_{\text {arb }}$ nunca sabe se aquilo ali que tá sendo falado é a realidade, se aquilo ali foi uma coisa montada pra aquele momento, sabe?

(12) Porque: é perto de tudo, $t u_{\text {arb }}$ não precisa se desloca(r), assim:, não, uma distância, assim, enorme pra fazer nada. $T u_{\text {arb }}$ vai no banco, $\boldsymbol{\emptyset}_{\text {arb }}$ vai aqui do lado, $\boldsymbol{\emptyset}_{\text {arb }}$ vai no mercado, tem aqui do lado [...].

As ocorrências da forma pronominal nula em (12) acontecem justamente em orações coordenadas, um contexto sintático favorecedor de sujeitos nulos amplamente reconhecido pela literatura. Repare que o tu em (11) e (12) não se refere ao interlocutor, que é o entrevistador, mas a uma referência genérica, que poderia ser parafraseado com “as pessoas” ou algo que o valha.

\footnotetext{
${ }^{8}$ Adotamos a nomenclatura "zero" para a estratégia em que o verbo aparece na $3^{\text {a }}$ pessoa do singular sem associação a qualquer índice de indeterminação, tal como propôs Vargas (2010) - veja os exemplos (9) e (10). Unimos as estratégias pronominais de segunda pessoa do singular (tu/você) por questões de variação diatópica: o pronome tu é muito mais frequente que o pronome você na fala vernacular de Porto Alegre (MONTEIRO, 1994; PERINI, 2016).

${ }_{9}^{9}$ Apesar de o pronome tu ser ainda largamente utilizado na fala cotidiana de Porto Alegre, sua flexão acontece com a forma verbal de $3^{\mathrm{a}}$ pessoa do singular, reduzindo o paradigma de flexão verbal, portanto.
} 
A segunda estratégia de indeterminação do sujeito mais recorrente no corpus (cerca de 1/4 dos dados) se deu com o uso da forma zero, em especial com a forma feita "tem que”, tal como vemos a seguir:

$$
\begin{aligned}
& {[\ldots] \text { não } \boldsymbol{\emptyset}_{\text {arb }} \text { tem que ter alguém dizendo pode ou não pode, acho que } \boldsymbol{\emptyset}_{\text {arb }} \text { tem }} \\
& \text { que poder }[\ldots] \text {. }
\end{aligned}
$$

$\emptyset_{\text {arb }}$ tem que te(r) policiamento ostensivo. Se não, não adianta. E a partir do momento que tive(r) policiamento, vai melhora(r) tudo, o comércio vai começa(r) a funciona(r) melhor ${ }^{10}$.

A terceira estratégia mais recorrente que encontramos foi a forma pronominal a gente, com 22\% de ocorrências, sendo usada como pronome arbitrário funcionando como sujeito indeterminado. Cabe destacarmos aqui a predominância de a gente sobre o pronome nós, com índice de apenas 8,3\%, algo que está relacionado, como dissemos na seção anterior, a uma tendência do PB contemporâneo - de maneira geral e não apenas no tocante à referência arbitrária - de preferência pela forma pronominal a gente em detrimento de nós. ${ }^{11}$

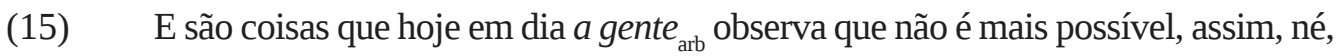
eu não, eu jamais levaria a minha filha pra um evento noturno... em Porto Alegre.

(16) [...] quando a gente $e_{\text {arb }}$ tem problemas de saúde, geralmente, e $\varnothing_{\text {arb }}$ fica tempo parada, a nossa cabeça começa questionar tudo na tua vida [...].

(17) [...] então, de repente, nós ${ }_{\text {arb }}$ podíamos falar, $\varnothing_{\text {arb }}$ podíamos berrar, $\varnothing_{\text {arb }}$ podíamos cantar, $\varnothing_{\text {arb }}$ podíamos tudo $[. .$.$] .$

Novamente, nesses exemplos, não temos referência determinada dos pronomes, mas uma referência indeterminada, arbitrária, em que os pronomes se referem antes a "pessoas em geral” do que ao locutor e seu interlocutor (ou ao locutor e alguma terceira pessoa). Em (17), encontramos novamente formas nulas em contexto de coordenação de orações.

Na sequência das formas mais frequentes, encontramos as estratégias de indeterminação recomendadas pela tradição gramatical: o uso da forma verbal na $3^{\mathrm{a}}$ pessoa do plural e o uso

\footnotetext{
${ }^{10}$ Um dos pareceristas fez-nos um comentário interessante, que pretendemos revisar na continuação de nossas investigações: “Os exemplos (13) e (14) envolvem construções com TER QUE deôntico. Poderiam ser trazidos mais outros dados - distintos desse tipo de estrutura - e verificar se $\emptyset_{\text {arb }}$ é frequente em outros contextos. Será que a estratégia $\emptyset_{\text {arb }}$ e a estratégia com o $S E$ não dizem respeito a uma mesma estratégia? Substitua o TER QUE por DEVER. Veja que não é de todo 'estranho' ou 'marginal' a coocorrência de dever com SE:

(13’) não se deve ter .... acho que se deve poder ...

(14') deve-se ter policiamento ostensivo ...

Em outras palavras, o $\boldsymbol{\emptyset}_{\text {arb }}$ poderia ser o “se” não expresso?”.

${ }^{11}$ Repare que a estratégia de indeterminação do sujeito reflete uma mudança ocorrida no quadro pronominal usado para a marcação de sujeitos com referência determinada em PB. Vemos aqui mais um efeito de encaixamento da mudança (LABOV, 2008): uma mudança no quadro pronominal do PB (o surgimento de a gente e seu uso com alta frequência no lugar de nós) gera um efeito cascata de mudanças que atingem e influenciam diferentes tipos de fenômenos gramaticais - a alteração na marcação do parâmetro pro-drop (DUARTE, 1995), a simplificação do paradigma de flexão verbal (LOPES, 1999, 2003), as regras de colocação pronominal (OTHERO; CARDOZO, 2017), as estratégias de indeterminação do sujeito, como vemos aqui (BARBOSA; RAMOS 2013; MENDONÇA, 2020), etc. Dois textos ilustrativos sobre o assunto podem ser vistos em Paiva e Duarte (2003) e Duarte (2018); a distinção entre nós e a gente como pronomes codificadores de referentes determinados ou de sujeito indeterminado é tratada por Mendonça (2020).
} 
do verbo na $3^{\text {a }}$ pessoa do singular com o se indeterminador. A forma eles (que, na amostra, também aparece expressa; veja o exemplo (19)) apresentou índice de 7\%, e o uso do se, 3,5\%. Vejamos alguns exemplos dessas ocorrências.

(18) Hoje em dia, só prédio, quase, $\emptyset_{\text {arb }}$ tão derrubando todas as casas.

(19) Que tipo de coisa que não se deve faze(r)?

(20) Aqui no centro:: tu não via, sabe, aqui na rua tu não via uma viatura. Ã: eles retiraram, ã na frente do HPS tinha um posto da brigada... Ã: que funcionava também vinte e quatro horas. Ã há pouco tempo atrás eles ${ }_{\text {arb }}$ retiraram o posto, sabe, foi uma coisa que fico(u) muito preocupante.

Em (18) e (19), temos sujeitos indeterminados canônicos, (18) expresso por sujeito nulo + verbo flexionado na $3^{\mathrm{a}}$ p. do plural, (19) por um se indeterminador do sujeito. Em (20), vemos um caso interessante. A exemplo do que mostramos em (4), temos aqui um sujeito expresso (eles) de referência arbitrária, que poderia ter sido omitido, mas não foi. Temos aí um contexto interessante, pois estão em competição duas formas idênticas à exceção da manifestação do pronome (verdadeiros "pares mínimos” sintáticos): sujeito nulolexpresso de referência arbitrária + verbo flexionado na $3^{\mathrm{a}}$ pessoa do plural.

Finalizando os dados da Amostra 2015, constatamos a existência de duas estratégias de indeterminação do sujeito não mencionadas nos estudos de Vargas (2010, 2012) - tampouco reconhecidas como estratégias de indeterminação pela tradição gramatical. Trata-se das formas vocês ( $2,2 \%$ das ocorrências) e eu (1,3\%) com referência arbitrária, como destacamos nos exemplos a seguir:

(21) Então, de repente, nós podíamos falar, podíamos berrar, podíamos cantar, podíamos tudo, então a gente fez coisas que vocês arb nem imaginam, nós fomos muito piores que vocês ${ }_{\text {arb }}$ são hoje, isso é uma coisa que vocês ${ }_{\text {arb }}$ também não enxergam, a falta de memória do adulto é dolorosa porque nós fomos muito, muito piores, muito, vocês $s_{\text {arb }}$ são maravilhosos, $\varnothing_{\text {arb }}$ são uns anjinhos perto do que a gente foi, nós somos sobreviventes, de repente, desse afã de liberdade que surgiu nos anos oitenta.

(22) [...] então é um problema de identidade muito () porque $e u_{\text {arb }}$ digo, ah, $e u_{\text {arb }}$ sou gaudério, mas nunca $\boldsymbol{\emptyset}_{\text {arb }}$ fui gaudério, tu é, essencialmente, urbano [...].

Em (21), o pronome vocês não se refere aos interlocutores - e nem poderia, pois não havia interlocutores, mas apenas um entrevistador. $\mathrm{O}$ pronome faz uma referência genérica à geração mais nova do que a do informante, em que ele compara a juventude de hoje com a sua própria juventude nos anos 1980. Talvez não se trate de uma referência completamente arbitrária que pudesse ser parafraseada com "as pessoas", mas certamente é um pronome que não está sendo empregado de maneira determinada, significando algo como "os jovens de hoje" de maneira genérica. Em (22), o informante está reportando um discurso comum no Rio Grande do Sul, em que pessoas se autoafirmam "gaudérias” (i.e. um gaúcho típico campeiro). Para isso, ela faz como que um discurso direto em que o pronome eu não têm referência definida - algo como 
“porque as pessoas dizem: ‘eu sou gaudério’”. Tanto o informante não fala de si mesmo que, na sequência, usa o tu arbitrário (não dirigido ao interlocutor e sem referência determinada).

Observamos também que todas as formas pronominais nominativas apresentam ocorrências com forma nula ou expressa. Na Tabela 3, apresentamos os resultados da distribuição dessas formas, que correspondem a um total de 162 dados.

Tabela 3: Distribuição das formas pronominais nominativas expressas e nulas

\begin{tabular}{c|c|c}
\hline \multicolumn{2}{c|}{ Formas pronominais expressas } & Formas nulas correspondentes \\
\hline tu/você & $66 / 69(95,7 \%)$ & $3 / 69(4,3 \%)$ \\
\hline a gente & $45 / 50(90 \%)$ & $5 / 50(10 \%)$ \\
\hline eles & $11 / 16(68,7 \%)$ & $5 / 16(31,3 \%)$ \\
\hline nós & $5 / 19(26,3 \%)$ & $14 / 19(73,7 \%)$ \\
\hline vocês & $4 / 5(80 \%)$ & $1 / 5(20 \%)$ \\
\hline eu & $2 / 3(66,3 \%)$ & $1 / 3(33,3 \%)$ \\
\hline Total & $\mathbf{1 3 3 / 1 6 2 ( 8 2 \% )}$ & $\mathbf{2 9 / 1 6 2 ( 1 8 \% )}$ \\
\hline
\end{tabular}

Fonte: Os autores.

Há uma clara preferência pela forma pronominal expressa em detrimento da forma nula: 82\% das ocorrências se dão com pronome foneticamente realizado (reforçando: a maioria das formas nulas que encontramos no corpus apareceu em orações coordenadas, um contexto favorecedor de retomadas anafóricas nulas). Não encontramos essa preferência pela forma pronominal preenchida apenas no pronome nós (aqui, ao contrário, temos 73,7\% das ocorrências com sujeito nulo). Ora, esse pronome é justamente o que apresenta a morfologia verbal mais marcada (podíamos, fazíamos, cantamos, etc.), um indício de que a morfologia verbal rica favorece o licenciamento da forma pronominal nula na função de sujeito (de qualquer maneira, não investigamos, aqui, os contextos específicos de ocorrência dos nulos com a forma pronominal nós).

Com os dados das duas amostras (Amostra 1990 e Amostra 2015) em mãos, esboçamos uma comparação entre as duas, que apresentamos na próxima seção.

\section{COMPARANDO AMOSTRAS}

Nesta seção, compararemos os resultados apresentados em Vargas (2010, 2012) para o último período analisado em seu estudo diacrônico acerca das estratégias de indeterminação do sujeito no PB (Amostra 1990) com os dados de nossa própria investigação no corpus LinguaPOA (Amostra 2015). Comecemos a comparação com a sistematização do Gráfico 3. 
Gráfico 3: Comparativo de ocorrência das estratégias de indeterminação em duas amostras ${ }^{12}$

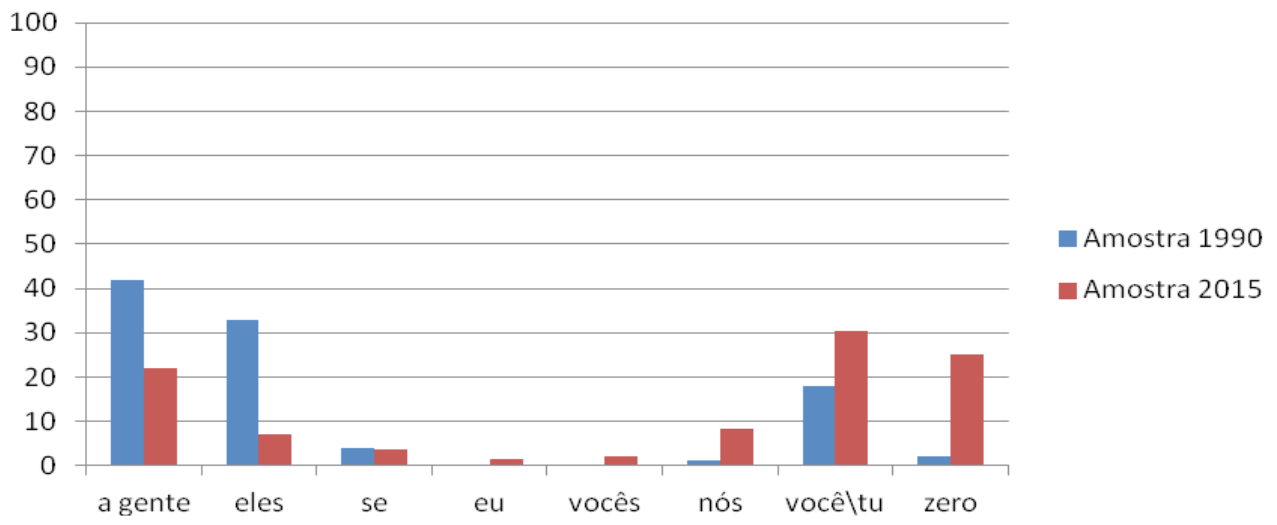

Fonte: Os autores.

Analisando o Gráfico 3, podemos elencar alguns pontos interessantes.

1. A forma de indeterminação com o clítico se apresentou índice de 4\% na Amostra 1990 e 3,5\% na Amostra 2015, o que sugere a manutenção dessa forma de indeterminação no intervalo de tempo analisado, levando-se em consideração a natureza distinta de cada corpus, evidentemente.

2. A forma pronominal de $3^{\text {a }}$ pessoa do plural (eles) apresentou uma queda significativa no comparativo entre a Amostra 1990 e a Amostra 2015: de 33\% na Amostra 1990 passou a representar apenas 7\% na Amostra 2015.

3. A forma nós apresentou, curiosamente, leve aumento: em vez de representar apenas 1\% das ocorrências de indeterminação do sujeito na Amostra 1990, passou a representar 8,3\% na Amostra 2015.

4. A forma a gente, por outro lado, apresentou uma queda, de $42 \%$ na Amostra 1990 para 22\% na Amostra 2015. Embora apresente queda significativa, essa forma ainda predomina sobre a estratégia de indeterminação com o pronome nós. ${ }^{13}$

5. A forma zero apresentou aumento significativo, de 2\% na Amostra 1990 para 25,11\% na Amostra 2015. É interessante notar que, na Amostra 1990, essa forma estava “entrando” no hall de estratégias de indeterminação do PB. Esse aumento significativo sugere uma implementação da forma no sistema e, conforme aponta Vargas (2010), pode indicar uma assimilação do "se” nos contextos não específicos (categorias aspectuais e de modalidade).

6. A forma de $2^{\mathrm{a}}$ pessoa do singular você/tu aumentou no comparativo: de $18 \%$ na Amostra 1990 a 30,3\% na Amostra 2015.

\footnotetext{
${ }^{12}$ Os dados correspondem aos percentuais apresentados nas duas amostras analisadas, detalhados nas seções 2 e 3.

${ }^{13}$ Elisa Battisti, em comunicação pessoal, alertou-nos para o seguinte fato: “[...] as constatações 3 e 4 me sugerem a necessidade de reconhecer que os dados da Amostra 2015, em razão de sua fonte (entrevistas sociolinguísticas), são dados de fala monitorada, em que se presta algum grau de atenção à fala, o que pode ter motivado o uso considerável de nós. O capítulo 3 ('O isolamento dos estilos contextuais') de Labov (2008) reconhece o monitoramento e aborda estilos contextuais (mais e menos monitorados) nas entrevistas. O que se poderia fazer é retornar aos dados e verificar o uso de nós/a gente em sentenças provenientes de trechos menos monitorados (mais próximos da fala coloquial) nas entrevistas. Aí se encontrariam elementos para reforçar o aumento ou relativizá-lo”.
} 
7. A Amostra 2015 apresenta duas estratégias de indeterminação do sujeito não encontradas na Amostra 1990: eu (1,3\%) e vocês (2,2\%), ainda com índices baixos de ocorrência, evidenciando o aparecimento de uma possível estratégia inovadora. Cabe destacar que (i) a forma pronominal eu aparece em contexto específico de discurso indireto, e (ii) a forma pronominal vocês é utilizada como estratégia de indeterminação que exclui o falante. Resta ver, em estudos futuros, se essas duas estratégias de indeterminação do sujeito começam a ganhar espaço.

Quanto à representação nula versus plena das formas nominativas nas duas amostras, o Gráfico 4 sintetiza a evolução dos resultados obtidos.

Gráfico 4: Representação das formas nulas e plenas nas duas amostras

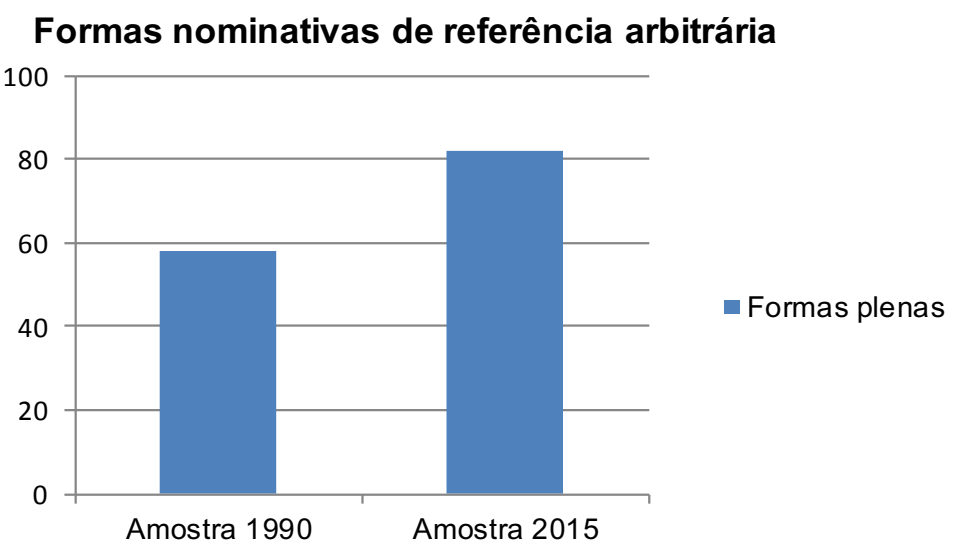

Fonte: Os autores.

Conforme já apontava Vargas (2010, 2012), no último período de tempo analisado, que corresponde aos dados da Amostra 1990, houve a prevalência das formas nominativas plenas de indeterminação sobre as nulas, com índice de 55\%. No intervalo de cerca de 25 anos entre a Amostra 1990 e a Amostra 2015, pudemos observar que a tendência ao uso de formas plenas de pronomes de referência arbitrária aumentou, e encontramos o pronome nominativo foneticamente produzido como estratégia de indeterminação do sujeito em 82\% das ocorrências na Amostra 2015 (versus 18\% de formas pronominais nulas). É o que mostramos na Tabela 2. Repare que estamos falando aqui apenas das estratégias inovadoras de indeterminação do sujeito em PB, isto é, o uso de formas pronominais nominativas (ver Gráfico 3). Além disso, encontramos no corpus - assim como Vargas (2010, 2012) - as estratégias “canônicas” de indeterminação do sujeito, seja com o “índice de indeterminação do sujeito” se, seja com o verbo na $3^{\mathrm{a}}$ pessoa do singular e uma posição de sujeito vazia, como verificamos nos exemplos anteriores.

\section{CONSIDERAÇÕES FINAIS}

O estudo aqui apresentado nos possibilitou chegar a conclusões interessantes acerca das estratégias de indeterminação do sujeito em PB. Inicialmente, observamos empiricamente que o PB recorre a diferentes estratégias além das tradicionalmente prescritas pelas gramáticas 
tradicionais. Entre essas estratégias está o uso dos pronomes pessoais nominativos com referência arbitrária.

Analisamos o estudo de Vargas (2010) para verificar a evolução das estratégias de indeterminação do sujeito ao longo dos séculos XIX e XX em PB. Depois disso, efetuamos nossa própria análise em dados bastante recentes de fala de PB vernacular contemporâneo (metade da segunda década do século XXI). Comparando os dados das duas amostras, podemos concluir que a entrada de novas formas de indeterminação no sistema gramatical do PB e a preferência pelo uso de formas plenas dos pronomes de referência arbitrária, acompanhando a preferência pelas formas plenas de referência determinada, são indícios da mudança pela qual o PB vem passando no que diz respeito ao favorecimento do sujeito expresso em detrimento do sujeito nulo, tal como vem argumentando Duarte em diversos trabalhos sobre o assunto desde a década de 1990 (conforme referências já citadas). Vemos aqui o efeito cascata de mudança já antecipado por Labov (2008), em que mudanças no quadro pronominal do PB, em especial aquelas que foram se estabelecendo a partir da metade do século XX, afetam diferentes aspectos da gramática da língua. A indeterminação do sujeito sendo um desses aspectos, como tentamos demonstrar aqui.

\section{AGRADECIMENTOS}

Agradecemos a leitura atenta e os comentários dos colegas Elisa Battisti (UFRGS) e Luisandro Mendes de Souza (UFPR), bem como as observações feitas por dois pareceristas anônimos da revista. Todos os equívocos do texto são de nossa inteira responsabilidade.

\section{REFERÊNCIAS}

BARBOSA, A. B.; RAMOS, C. M. A. Uso das formas pronominais tu, você e a gente como estratégia de indeterminação do sujeito: o que mostram os dados do ALiMA. Cadernos de Pesquisa, São Luís, v. 20, n. especial, p. 89-98, jul. 2013. DOI: http://dx.doi.org/10.18764/21782229.v20n.especialp89-98

BARROS JESUS, G. A indeterminação do sujeito no português popular de Salvador. 2017. 120 f. Dissertação (Mestrado em Letras) - Instituto de Letras, Universidade Federal da Bahia, Salvador, 2017.

BATTISTI, E. et al. LínguaPOA, acervo de entrevistas sociolinguísticas em constituição: desenho da amostra e resultados dos primeiros estudos. In: SEMINÁRIO DE TEORIA E ANÁLISE LINGUÍSTICA - SETAL, 2017, Porto Alegre. Proceedings [...]. Porto Alegre: Setal, 2017.

BERLINK, R. A.; DUARTE, M. E. L.; OLIVEIRA, M. Predicação. In: KATO, M.; NASCIMENTO, M. (org.). Gramática do português culto falado no Brasil: a construção da sentença. São Paulo: Contexto, 2015. p. 81-149.

CUNHA, C.; CINTRA, L. Nova gramática do português contemporâneo. 6. ed. Rio de Janeiro: Lexikon, 2013. 
CYRINO, S. M. O objeto nulo no português do Brasil: um estudo sintático-diacrônico. Londrina: Editora da Universidade Estadual de Londrina, 1997.

DUARTE, M. E. L. A perda do princípio “Evite Pronome” no português brasileiro. 1995. 151 f. Tese (Doutorado em Ciências) - Instituto de Estudos da Linguagem, Universidade Estadual de Campinas, Campinas, 1995.

DUARTE, M. E. L. A evolução na representação do sujeito pronominal em dois tempos. In: PAIVA, M. da C.; DUARTE, M. E. L. (org.). Mudança linguística em tempo real. Rio de Janeiro: ContraCapa/FAPERJ, 2003. p. 115-128.

DUARTE, M. E. L. Clítico acusativo, pronome lexical e categoria vazia no português do Brasil. In: TARALLO, F. (org.). Fotografias sociolingüísticas. Campinas: Editora da Unicamp, 1989. p. 19-34.

DUARTE, M. E. L. Do pronome nulo ao pronome pleno: a trajetória do sujeito no português do Brasil. In: ROBERTS, I.; KATO, M. A. (org.). Português brasileiro: uma viagem diacrônica. Campinas: Editora da UNICAMP, 1993. p. 107-128.

DUARTE, M. E. L. (org.) O sujeito em peças de teatro (1833-1992): estudos diacrônicos. São Paulo: Parábola, 2012.

DUARTE, M. E. L. ReVEL na Escola: sobre pronomes pessoais na fala e na escrita. ReVEL, [s. l.], v. 16, n. 30, p. 1-12, 2018.

DUARTE, M. E. L. Sujeitos de referência definida e arbitrária: aspectos conservadores e inovadores na escrita padrão. Linguística, Rio de Janeiro, v. 3, n. 1, p. 89-115, jun. 2007. DOI: https://doi.org/10.31513/linguistica.2007.v3n1a4396

DUARTE, I.; FIGUEIREDO SILVA, M. C. The null subject parameter and the structure of the sentence in European and Brazilian Portuguese. In: WETZELS, L.; COSTA, J.; MENUZZI, S. M. (org.). The handbook of Portuguese Linguistics. West Sussex: Wiley Blackwell, 2016. p. 234-253.

LABOV, W. Padrões sociolinguísticos. Tradução Marcos Bagno, Maria Marta P. Scherre, Caroline R. Cardoso. São Paulo: Parábola Editorial, 2008.

LOPES, C. R. S. A inserção de 'a gente’ no quadro pronominal do português. Frankfurt am Main/Madrid: Vervuert/Iberoamericana, 2003. v. 18.

LOPES, C. R. S. A inserção de a gente no quadro pronominal do português: percurso histórico. 1999. 174 f. Tese (Doutorado em Letras) - Faculdade de Letras, Universidade Federal do Rio de Janeiro, Rio de Janeiro, 1999.

LOPES, C. R. S. Pronomes pessoais. In: BRANDÃO, S. F.; VIEIRA, S. R. (org.). Ensino de gramática: descrição e uso. São Paulo: Contexto, 2007. p. 103-119.

MENDONÇA, J. de J. Interpretação de pronomes de primeira pessoa do plural. Caderno de Squibs: Temas em Estudos Formais da Linguagem, Brasília, v. 4, n. 2, p. 45-54, 2020.

MENON, O. S. P. O sistema pronominal do português. Revista Letras, Curitiba, n. 44, p. 91106, 1995. DOI: http://dx.doi.org/10.5380/rel.v44i0.19069 
MONTEIRO, J. L. Pronomes pessoais. Fortaleza: EUFC, 1994.

OTHERO, G. A.; CARDOZO, R. W. A ordem pronominal em português brasileiro: da ênclise à próclise, do clítico ao tônico (or There and Back Again, a Word Order's Holiday). Fórum Linguístico, Florianópolis, v. 14, n. 1, p. 1717-1734, jan./mar. 2017. DOI: http://dx.doi. org/10.5007/1984

OTHERO, G. A. et al. Objeto nulo e pronome pleno na retomada anafórica em PB: uma análise em corpora escritos com características de fala. Revista da Anpoll, Florianópolis, v. 1, n. 45, p. 68-89, maio/ago. 2018. DOI: https://doi.org/10.18309/anp.v1i45.1113

OTHERO, G. A.; SPINELLI, A. C. Sujeito pronominal expresso e nulo no começo do séc. XXI (e sua relação com o objeto nulo em PB). Domínios de Lingu@gem, Uberlândia, v. 13, n. 1, p. 7-33, 2019. DOI: https://doi.org/10.14393/DL37-v13n1a2019-1

PAIVA, M. C.; DUARTE, M. E. L. Introdução: a mudança linguística em curso. In: PAIVA, M. C.; DUARTE, M. E. L. (org.). Mudança linguística em tempo real. Rio de Janeiro: Contra Capa, 2003. p. 13-29.

PERINI, M. A. Gramática descritiva do português brasileiro. Petrópolis: Vozes, 2016.

SETTI, A. C. R. A indeterminação do sujeito nas três capitais do sul do Brasil. 1998. 124

f. Dissertação (Mestrado em Letras) - Universidade Federal do Paraná, Curitiba, 1998.

VARGAS, A. S. C. Estratégias pronominais de indeterminação: um estudo diacrônico. 2010. 104 f. Dissertação (Mestrado em Letras Vernáculas - Língua Portuguesa) - Universidade Federal do Rio de Janeiro, Rio de Janeiro, 2010.

VARGAS, A. S. C. A evolução na representação das estratégias pronominais de indeterminação. In: DUARTE, M. E. L. (org.). O sujeito em peças de teatro (1833-1992): estudos diacrônicos. São Paulo: Parábola, 2012. p. 45-67.

ZILLES, A. M. S. Grammaticalization of ‘a gente’ in Brazilian Portuguese. Working Papers in Linguistics, Philadelphia, v. 8, n. 3, p. 297-310, 2002.

Recebido em: jun. 2020.

Aceito em: jul. 2020. 